\title{
A PTFE membrane for the in situ extraction of dissolved gases in natural waters: Theory and applications
}

\author{
S. De Gregorio and S. Gurrieri \\ Istituto Nazionale di Geofisica e Vulcanologia Sezione di Palermo, Via Ugo La Malfa 153, 90146 Palermo, Italy \\ (s.degregorio@pa.ingr.it)
}

\section{Valenza \\ Dipartimento di Chimica e Fisica della Terra ed Applicazioni, Via Archirafi 36, 90136 Palermo, Italy}

[1] A new method for extracting dissolved gases in natural waters has been developed and tested, both in the laboratory and in the field. The sampling device consists of a polytetrafluroethylene (PTFE) tube (waterproof and gas permeable) sealed at one end and connected to a glass sample holder at the other end. The device is pre-evacuated and subsequently dipped in water, where the dissolved gases permeate through the PTFE tube until the pressure inside the system reaches equilibrium. A theoretical model describing the time variation in partial gas pressure inside a sampling device has been elaborated, combining the mass balance and "Solution-Diffusion Model" (which describes the gas permeation process through a PTFE membrane). This theoretical model was used to predict the temporal evolution of the partial pressure of each gas species in the sampling device. The model was validated by numerous laboratory tests. The method was applied to the groundwater of Vulcano Island (southern Italy). The results suggest that the new sampling device could easily extract the dissolved gases from water in order to determine their chemical and isotopic composition.

Components: 7885 words, 10 figures, 5 tables.

Keywords: dissolved gases; helium isotope; PTFE membrane; Vulcano Island.

Index Terms: 1041 Geochemistry: Stable isotope geochemistry (0454, 4870); 1094 Geochemistry: Instruments and techniques.

Received 21 February 2005; Revised 19 May 2005; Accepted 20 June 2005; Published 7 September 2005.

De Gregorio, S., S. Gurrieri, and M. Valenza (2005), A PTFE membrane for the in situ extraction of dissolved gases in natural waters: Theory and applications, Geochem. Geophys. Geosyst., 6, Q09005, doi:10.1029/2005GC000947.

\section{Introduction}

[2] The study of the chemical and isotopic composition of the dissolved gases in natural waters is a very useful tool in several branches of the earth sciences, e.g., hydrology, volcano monitoring and earthquake prediction [Gurrieri et al., 1984; D'Alessandro et al., 1997; Allard et al., 1997; Sano et al., 1998; Capasso et al., 2000; Italiano et al., 2004]. Dissolved gases can also be used as environmental tracers in groundwater dating techniques and in the determination of recharge temperature [Mazor, 1977; Andrews et al., 1989; Stute et al., 1995; Sanford et al., 1996; Solomon et al., 1998; Aeschbach-Hertig et al., 1999; Peeters et al., 2002; Manning and Solomon, 2003]. Furthermore, the study of dissolved gases occupies an important role both in freshwater biochemistry and oceanography [Kana et al., 1994; McNeil et al., 1995; Chapelle et al., 1997; Emerson et al., 2002].

[3] Different methods have been developed in order to separate the dissolved gaseous phase from 
liquid water. They can be divided into two main groups: the laboratory extraction technique (LET) and the field extraction technique (FET). LET methodologies are based on three different techniques: the vacuum extraction technique (VET), the equilibration extraction technique (EET) and the bubble extraction technique (BET). In the VET, a water sample is usually collected with a special copper tube or glass vessel with stopcocks, after which the dissolved gases are extracted, following a specific procedure in the laboratory which involves a vacuum line. This method is widely used for noble gas analysis [Weiss, 1968; Mazor, 1977; Andrews et al., 1985; Bayer et al., 1989; Ludin et al., 1997; Beyerle et al., 2000]. Another VET method separates the dissolved gases from a water sample, which has been collected in a Schlenk bottle. The bottle is connected to a vacuum line and dipped in an ultrasonic bath [Holt et al., 1995]. This line is equipped with cold traps and a complex valve system with which to separate each gas species.

[4] The EET technique is based on the gas partitioning equilibrium between the liquid and gas phases, and it involves the collection of a water sample in a glass flask of known volume and its equilibrium with a host gas. According to Henry's law, the host gas dissolves in water and, simultaneously, the dissolved gases pass from the liquid phase to the gas phase until equilibrium is reached. The total amount of dissolved gases is computed by the partitioning equilibrium between the gas and the liquid, where the equilibrium can be mainly obtained in two ways: either a known volume of the host gases is injected into a glass flask, which draws out the equivalent water volume [Capasso and Inguaggiato, 1998; Inguaggiato and Rizzo, 2004] or the host gas and water sample are inserted into a special injector [Sugisaki and Taki, 1987]. Finally, the bubble extraction method (BET) was mainly developed to detect dissolved hydrocarbons in environmental research. It consists of the equilibration of a water sample in a bulb, with a headspace filled with an inert gas. The water is pumped through the bulb until equilibrium is reached [Walsh and McLaughlan, 1999].

[5] The FET methodologies can be divided into two main groups: the field bubble extraction technique (FBET) and passive diffusion technique (PDT). The FBET and the BET are based on the same principle but, in the former, the gas extraction is performed in situ [Tonani, 1971; Chapelle et al., 1997; Kampbell et al., 1998]. The PDT is based on the use of semipermeable membranes, which are generally in the form of a polydimetylsilicone (PDMS) tubes. Passive diffusion samplers, consisting of a copper tube sealed at one end and connected to a sealed silicone tube at the other, have been developed by Sanford et al. [1996]. The samplers are dipped in water for a sufficient period of time in order to re-equilibrate the sampler headspace via permeation through the silicone tube. When complete re-equilibration has been reached, the samplers are removed and closed by crimping. Jacinthe and Groffman [2001] have developed another PDT device, consisting of a PVC pipe with internal PDMS tube. The water flows into the space between the pipe and the PDMS tube and the dissolved gases permeate through the PDMS tube. Takahata et al. [1997] assembled an apparatus for the continuous monitoring of dissolved noble gases in water which were then analyzed using a Quadrupole Mass Spectrometer with a remote controller. The gas separation is performed in situ, by a semipermeable polypropylene film membrane, located at the head of a sampling probe and dipped into water. As suggested by these authors, the separation is performed by evacuating the inside of the tubing slowly.

[6] A field VET, consisting of a glass bottle (preevacuated) which is partially filled with a water sample, has been performed by Chiodini [1996]. According to Henry's law, the gases partitioned between the gas and the liquid phase and the total amount of single dissolved gas is recalculated with known volumes of the liquid and gas phases and the chemical composition of the gas phase.

[7] A comparison of the aforementioned methods suggests some general considerations. The most important shortcoming of LETs regards the collecting and handling of the water sample; this can involve several random accidents, such as the partial out gassing of dissolved gases and/or sample contamination with air micro-bubbles. The FETs necessitate more time spent in the field but they supply gas samples that do not require further laboratory equilibration. Otherwise, the FETs cannot generally furnish the total pressure of dissolved gases (TDGP) but only gas concentrations. In order to solve these disadvantages, Manning et al. [2000] have recently coupled Sanford's method with a TDGP probe. Despite the numerous methods developed, it is necessary to collect more samples by different techniques in order to perform the chemical and isotopic analyses of dissolved gases. 


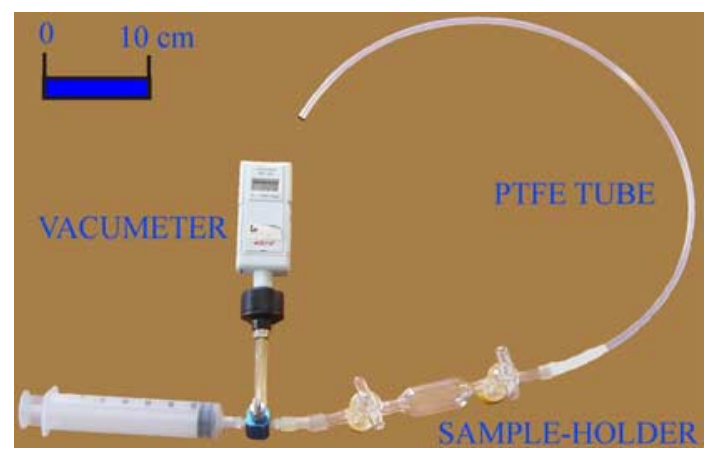

Figure 1. Sampling device and vacuum system control. The PTFE tube is sealed at one end and connected to the sample holder at the other end. The syringe is used to evacuate the system. The function of the vacumeter is to control the evacuation process of the sampling device before dipping it in natural waters.

[8] This paper describes a new in situ method (FET-PDT), using a polymeric semipermeable membrane, for extracting the dissolved gaseous phase from natural waters. The method consists of a very simple sampling device and a mathematical model to recalculate the gas partial pressures at equilibrium by less than fully equilibrated samples. Furthermore, this method provides a unique gas sample for chemical and isotopic analyses. Another significant advance of the proposed method is the capability to collect an in situ sample of dissolved gases from deep wells without a pump. Such wells are the best places to effect a periodical and continuous monitoring of dissolved gases, with the aim of volcano surveillance. Furthermore, this method enables a concentration profile of lakes, seas and rivers to be easily performed. This paper also shows the results of a field application of the new method in an active volcanic area (Vulcano Island, southern Italy).

\section{Method and Materials}

\subsection{Analytical Procedure}

[9] The dissolved gases $\left(\mathrm{O}_{2}, \mathrm{~N}_{2}, \mathrm{CH}_{4}\right.$ and $\left.\mathrm{CO}_{2}\right)$ were analyzed by gas chromatography (G.C.) Perkin-Elmer mod. 8500, equipped with 4-m carbosieve II columns, hot wire and flame ionization detectors; Ar was the carrier gas and the instrumental precision of the G.C. was $\pm 3 \%$. In order to measure the quantity of noble gases, gas samples were purified in a high-vacuum line equipped with a charcoal trap, a cold trap and getter pumps. The first purified fraction, consisting of $\mathrm{He}$ and $\mathrm{Ne}$, was analyzed using a quadrupole mass spectrometer
(QMS, VG Quartz). Finally, the He was totally isolated and analyzed with a static vacuum mass spectrometer MS (VG-5400TFT, VG Isotopes), which had been specifically modified to simultaneously detect ${ }^{3} \mathrm{He}$ and ${ }^{4} \mathrm{He}$ ion beams. The ${ }^{3} \mathrm{He} /{ }^{4} \mathrm{He}$ ratio was determined by measuring ${ }^{3} \mathrm{He}$ with a Daly electron multiplier detector, and ${ }^{4} \mathrm{He}$ with a Faraday cup detector. The results have been reported as $\mathrm{R} / \mathrm{Ra}$ values $\left(\mathrm{R}\right.$ is the ratio of ${ }^{3} \mathrm{He} /{ }^{4} \mathrm{He}$ in the sample and $\mathrm{Ra}$ is the ratio of ${ }^{3} \mathrm{He} /{ }^{4} \mathrm{He}$ in air $=$ $1.39 \cdot 10^{-6}$ [Ozima and Podosek, 2002]).

\subsection{Extraction Procedure}

[10] In order to effectively extract dissolved gases from the liquid phases, the separation membranes would have to be characterized by the following fundamental properties: being waterproof, stiff, and chemically and biologically inactive. These properties are common in the solid synthetic polymeric membrane group. In such polymers, the gas permeation is essentially confined to the amorphous regions while the crystalline regions represent tortuous impediments to gas permeation but they confer good mechanical proprieties to the polymer. In general, the gas permeation rate is inversely proportional to its mechanical properties.

[11] The method described in this paper is based on the use of a membrane made of polytetrafluroethylene (PTFE). This material was selected because it represents the best compromise between gas permeation rates and mechanical and chemical properties. The high crystallinity confers stiffness and high tolerance to PTFE, which is sufficient to bear mechanical stress. Furthermore, PTFE resists bacterial growth and every known chemical agent or solvent at low and high temperatures (PTFE melting point $=327^{\circ} \mathrm{C}$, useful temperature up to $\left.260^{\circ} \mathrm{C}\right)$.

[12] The sampling device used for extracting dissolved gases in natural water consists of a PTFE tube connected to a glass sample holder with two stopcocks (Figure 1). The PTFE tube is a semipermeable membrane, which allows the permeation of gas inside the system, while the glass sample holder stores the extracted gases. Before use, the device is evacuated, using a syringe, and dipped into water (wells, springs, lakes or rivers). Throughout the immersion period, the stopcock between the semipermeable membrane and the glass sample holder is left open. After an established exchange time, when equilibrium has been totally or partially reached, the stopcock is closed in order to isolate the extracted gases inside the sample holder and 

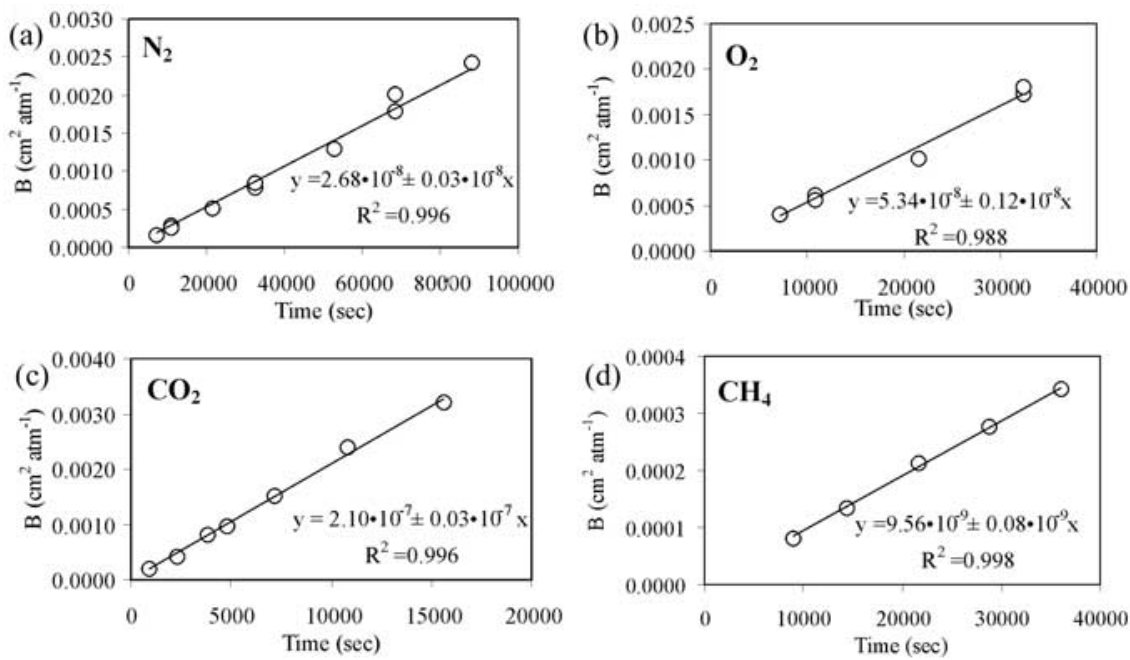

Figure 2. Determination of the Kp PTFE (a) nitrogen, (b) oxygen, (c) carbon dioxide, and (d) methane. Each linear best fit represented the $\mathrm{Kp}$ of the $i$ th gas species (see text). The variation in time range on the graphs depends on the different equilibration time. The $\mathrm{N}_{2}$ data range over 100,000 seconds and the $\mathrm{O}_{2}$ data range over 40,000 seconds because, after this period, the $\mathrm{O}_{2}$ has reached equilibrium and no further variation in $\mathrm{O}_{2}$ partial pressure was recorded.

prevent diffusion phenomena through the membrane after the device has been removed from the water.

\subsection{Theoretical Model}

[13] Gas transport through a dense nonporous membrane, such as PTFE, can be described by the Solution-Diffusion Model [Barrer, 1934; Van Amerongen, 1946; Wijmans and Baker, 1995], according to which the gas on the high-pressure side of the membrane dissolves in the membrane body and, due to a concentration gradient, diffuses toward the low-pressure side of the same membrane, where the gas is finally desorbed. The law governing the flux through the membrane is

$$
\mathrm{J}_{\mathrm{i}}=\mathrm{K}_{\mathrm{p}} \frac{\Delta p}{\mathrm{~h}},
$$

where $\mathrm{J}_{\mathrm{i}}$ is the flux $\left(\mathrm{cm}^{3}\right.$ STP $\left.\mathrm{cm}^{-2} \mathrm{sec}^{-1}\right)$, $\mathrm{Kp}$ is the permeability coefficient $\left(\mathrm{cm}^{3}\right.$ STP $\left.\mathrm{cm}^{-1} \mathrm{sec}^{-1} \mathrm{~atm}^{-1}\right), \Delta \mathrm{P}$ is the pressure difference (atm) and $\mathrm{h}$ is the membrane thickness $(\mathrm{cm})$.

[14] The mass balance, given by the continuity equation, is

$$
\mathrm{dM}(\mathrm{t})=\mathrm{VdP}_{\mathrm{i}}(\mathrm{t})=\mathrm{J}_{\mathrm{i}} \cdot \mathrm{A} \cdot \mathrm{dt},
$$

where $\mathrm{V}$ is the internal volume of the device, $\mathrm{P}_{\mathrm{i}}$ is the partial pressure of gas inside the device, $\mathrm{J}_{\mathrm{i}}$ is the gas flux, referring to a unity surface, of the species permeating through the membrane and $\mathrm{A}$ is the membrane surface. Combining equations (1) and (2), the following equation is obtained:

$$
\operatorname{VdP}_{\mathrm{i}}(\mathrm{t})=\mathrm{K}_{\mathrm{p}} \times \mathrm{A} \frac{\mathrm{P}_{\mathrm{a}}-\mathrm{P}_{\mathrm{i}}(\mathrm{t})}{\mathrm{h}} \mathrm{dt},
$$

which has the solution

$$
P_{i}(t)=P_{a}+a \cdot e^{-\frac{K_{p} \cdot A}{V h} t},
$$

where $\mathrm{P}_{\mathrm{i}}(\mathrm{t})$ is the partial pressure of the $i$ th gas at time $t$ inside the sampling device, $\mathrm{P}_{\mathrm{a}}$ is the partial pressure of $i$ th gas dissolved in the water and a is a constant which depends on initial system conditions. If, at time $t=0$, the initial partial pressure $\left(\mathrm{P}_{\text {in }}\right)$ of the $i$ th gas inside the device is zero $\left(\mathrm{P}_{\mathrm{i}}(0)=\right.$ $\left.\mathrm{P}_{\text {in }}=0\right), \mathrm{a}$ is equal to $-\mathrm{P}_{\mathrm{a}}$ and equation (4) becomes

$$
\mathrm{P}_{\mathrm{i}}(\mathrm{t})=\mathrm{P}_{\mathrm{a}}\left(1-\mathrm{e}^{-\frac{\mathrm{K}_{\mathrm{P}} \cdot \mathrm{A}}{\mathrm{Vh}} \mathrm{t}}\right),
$$

and according to Dalton's law,

$$
P_{i}(t)=\left(X_{a} \cdot P_{t}\right) \cdot\left(1-e^{-\frac{K_{p} \cdot A}{V h} t}\right) .
$$

If $\mathrm{P}_{\mathrm{i}}(0)=\mathrm{P}_{\text {in }} \neq 0, \mathrm{a}=\mathrm{P}_{\text {in }}-\mathrm{P}_{\mathrm{a}}$, equation (4) becomes

$$
P_{i}(t)=P_{a}+\left(P_{i n}-P_{a}\right) \cdot e^{-\frac{K_{p} \cdot A}{V h} t} .
$$




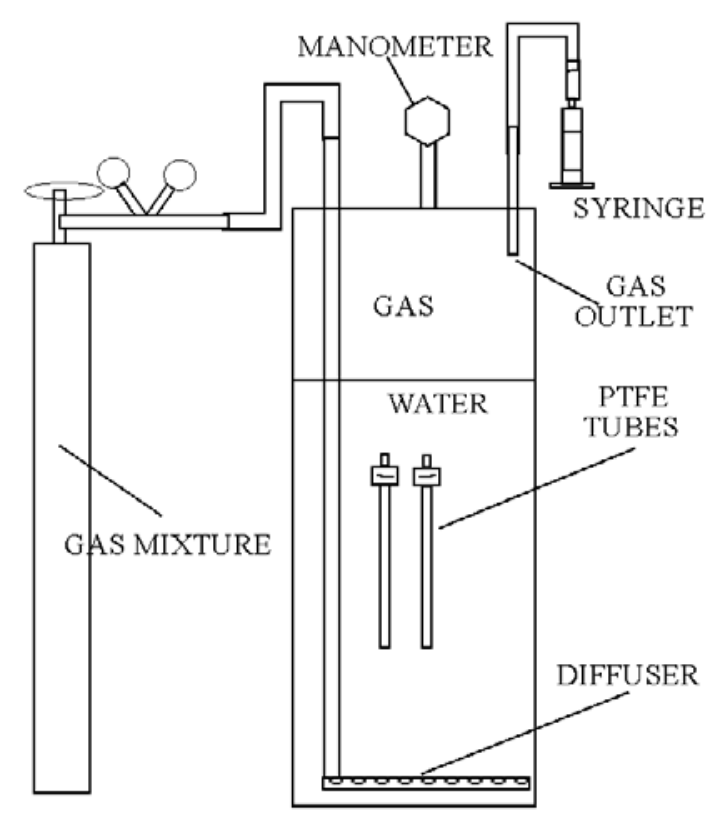

Figure 3. Sketch of apparatus used to compute the Kp of PTFE. The gas mixture was dissolved in water by the diffuser. In order to rigorously check the equilibrium partial pressure, a syringe was used to collect a sample of the equilibrated gas phase over water.

The above equations describe the time variation in the partial pressure of the $i$ th gas species inside the device under different initial conditions.

\subsection{Experimental Parameters}

[15] In order to use the above equations, the geometric characteristics of the device and the PTFE permeability coefficients $(\mathrm{Kp})$ for each gas species must be known. The cylinder radius and wall-thickness were directly measured while the $\mathrm{Kp}$ values were experimentally determined from the theoretical model. Rearranging the general equation (5), we have

$$
\left[\ln P_{a}-\ln \left(P_{a}-P_{i}\right)\right] \cdot \frac{V h}{A}=K_{p} t
$$

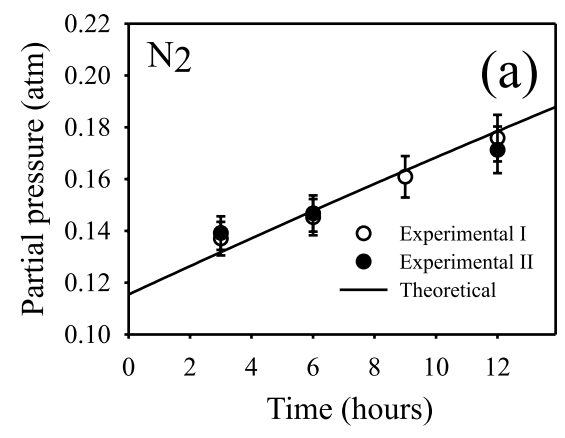

and setting

$$
\begin{aligned}
& B=\left[\ln P_{a}-\ln \left(P_{a}-P_{i}\right)\right] \cdot \frac{V h}{A} \\
& B=K_{p} t
\end{aligned}
$$

The $\mathrm{Kp}$ values were determined from equation (9) by calculating the angular coefficient of the best fitting line for all the data (Figure 2).

[16] The Kp values for nitrogen and oxygen were calculated by assembling a simple device, consisting of a PTFE tube closed at one end and connected to a three-way stopcock at the other end. The device was dipped into a thermostat bath filled with air-saturated water (ASW) and left there for different time periods. Initially, the gas partial pressure of the atmospheric gases $\left(\mathrm{N}_{2}\right.$ and $\left.\mathrm{O}_{2}\right)$ inside the PTFE tubes was equal to zero because each tube was filled with argon at atmospheric pressure. Pi(t) was measured for seven different extraction time periods and, in some cases, two tubes were used at the same time under the same boundary conditions to verify experimental reproducibility. All the tests were carried out at $1 \mathrm{~atm}$ at a temperature of $24^{\circ} \mathrm{C}$ and no significant variations in the main atmospheric parameters (temperature and pressure) occurred during all the experiments. The gaseous phases inside the PTFE tubes were analyzed with the G.C. and the measured values are shown in Figures $2 \mathrm{a}$ and $2 \mathrm{~b}$.

[17] The determination of the $\mathrm{Kp}$ values for $\mathrm{CH}_{4}$ and $\mathrm{CO}_{2}$ were performed by using the same device in a special system, which consisted of an exchanging bath and gas diffuser (Figure 3). The diffuser was connected to a tank containing a gas mixture of known composition. In order to effect a rigorous control on equilibrium partial pressure $\left(\mathrm{P}_{\mathrm{a}}\right)$ during the tests, the gas phase inside the system was monitored by periodic sampling and analyses. The results of the experiments have been illustrated

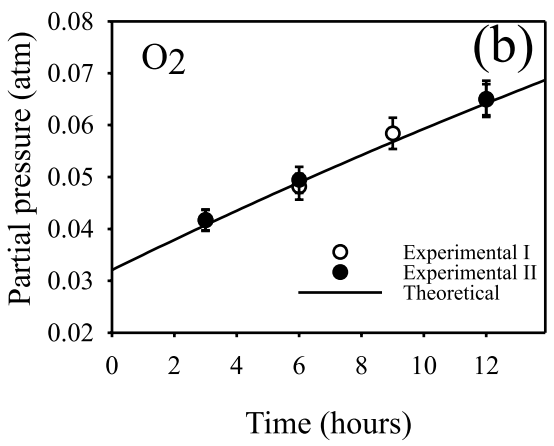

Figure 4. Comparison between theoretical (line) and experimental partial pressures (open and solid circles): (a) nitrogen and (b) oxygen. The error bar in each point indicates the instrumental precision $( \pm 3 \%)$. 
Table 1. Partial Pressure of Atmospheric Gases Inside Devices of Different PTFE Tube Lengths

\begin{tabular}{|c|c|c|c|c|c|c|}
\hline Sample & $\mathrm{PiO}_{2},{ }^{\mathrm{a}}$ atm & $\mathrm{PiN}_{2}$, atm & $\mathrm{PaO}_{2},{ }^{\mathrm{b}}$ atm & $\mathrm{PaN}_{2}$, atm & Pin, atm & $\mathrm{L}, \mathrm{cm}$ \\
\hline 1 & 0.08 & 0.29 & 0.14 & 0.78 & 0.121 & 40 \\
\hline 2 & 0.08 & 0.27 & 0.14 & 0.79 & 0.090 & 40 \\
\hline 3 & 0.09 & 0.39 & 0.13 & 0.78 & 0.090 & 90 \\
\hline 4 & 0.10 & 0.40 & 0.13 & 0.77 & 0.121 & 90 \\
\hline 5 & 0.11 & 0.47 & 0.13 & 0.78 & 0.121 & 140 \\
\hline
\end{tabular}

${ }^{a} P_{i}$ is the partial pressure of atmospheric gases inside devices after 71 hours.

${ }^{\mathrm{b}} \mathrm{P}_{\mathrm{a}}$ is the computed partial pressure according to recalculation model.

in Figures 2c and 2d. The Kp value for He was computed by two experiments, with a partial equilibrium pressure equal to $5 \cdot 10^{-4}$ atm, directly using equation (9): $\mathrm{Kp}_{\text {Helium }}=2.6 \cdot 10^{-7} \mathrm{~cm}^{3} \mathrm{STP} \mathrm{cm}^{-1}$ $\mathrm{atm}^{-1} \mathrm{sec}^{-1}$.

\subsection{Recalculation Method}

[18] A theoretical method, recalculation method (R.M.), for calculating the gas partial pressures in equilibrium with the water from the disequilibrium experimental data was elaborated, starting from the theoretical model. From equation (7), which describes the concentration variation inside the system, it follows that

$$
\begin{aligned}
P_{i}(t) & =P_{a}+P_{i n} e^{-\frac{K_{p} \cdot A}{P_{h}} t}-P_{a} e^{-\frac{K_{p} \cdot A}{V h} t} \\
P_{i}(t) & =P_{a}\left(1-e^{-\frac{K_{p} \cdot A}{h} t}\right)+P_{i n} e^{-\frac{K_{p} \cdot A}{V h} t} \\
P_{a} & =\frac{P_{i}(t)-P_{i n} e^{-\frac{K_{p} \cdot A}{V_{h}} t}}{1-e^{-\frac{K_{p} \cdot A}{V h} t}}
\end{aligned}
$$

This final equation allows us calculate the real equilibrium pressure of the dissolved gases in water, knowing the partial pressure of the $i$ th gas species inside the sample holder after the exchange time $\left(\mathrm{P}_{\mathrm{i}}\right)$, the initial partial pressure of the $i$ th gas species $\left(\mathrm{P}_{\text {in }}\right)$ and the exchange time $(\mathrm{t})$.

\section{Laboratory Tests}

[19] In order to verify the theoretical model and reliability of the recalculation method, several tests were performed in the laboratory. The main objective of the first test was to obtain experimental data regarding the time variation in the partial pressure of the atmospheric gases inside the sampling device. Eight sampling devices, assembled with glass sample-holders and a PTFE tube with the same geometric characteristics, were placed in ASW. The initial partial pressure inside each device was equal to $0.148 \mathrm{~atm}$. At four different time intervals (3, 6, 9 and 12 hours), two sampling devices were removed and the gas composition was analyzed using the G.C. Figures $4 \mathrm{a}$ and $4 \mathrm{~b}$ show the comparison between the theoretical model and experimental data. The close agreement between the two sets of data sets confirms the reliability of the theoretical model.
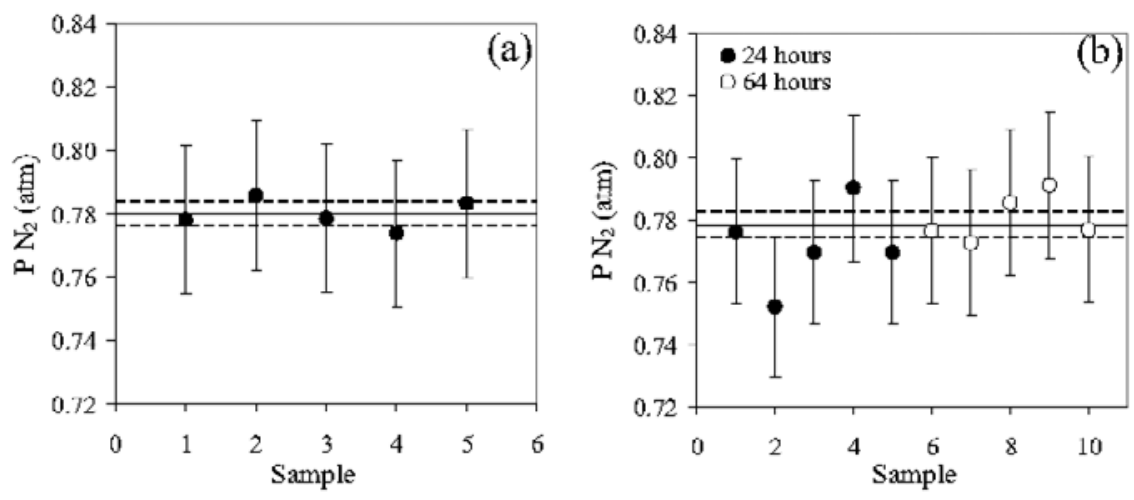

Figure 5. Values of $\mathrm{N}_{2}$ partial pressure, computed by the recalculation model from the values of $\mathrm{N}_{2}$ partial pressure inside (a) five sampling devices dipped in ASW for 71 hours and (b) ten sampling devices in ASW after 24 hours (solid circles) and 64 hours (open circles), respectively. In both figures the solid line represents the equilibrium $\mathrm{N}_{2}$ partial pressure, the dashed lines define the analytical uncertainty of the barometric pressure $(0.005 \mathrm{~atm})$, and the error bar in each point indicates instrumental precision $( \pm 3 \%)$. 
Table 2. He Isotope Reproducibility Tests

\begin{tabular}{lcc}
\hline Sample & Time, hours & $\mathrm{R} / \mathrm{Ra}$ \\
\hline ASW1 & 12 & $0.97 \pm 0.05$ \\
ASW2 & 24 & $1.00 \pm 0.04$ \\
ASW3 & 24 & $1.06 \pm 0.06$ \\
ASW4 & 24 & $0.99 \pm 0.06$ \\
\hline
\end{tabular}

[20] The devices used in the second test comprised five equal sample-holders joined to PTFE tubes of three different lengths $(40,90$ and $140 \mathrm{~cm})$. The initial gas pressure inside the devices ranged from 0.09 to $0.121 \mathrm{~atm}$ of air. The devices were dipped in ASW for 71 hours, then the $\mathrm{N}_{2}$ and $\mathrm{O}_{2}$ contents were determined by the G.C. As predicted by the theoretical model, the pressures inside the sample-holder were proportional to the length of the PTFE tubes (Table 1). This indicated that 71 hours of exchange time were not sufficient to reach total equilibrium between the dissolved and separated gas phase. Therefore the values were processed in accordance with equation (10). Regarding the nitrogen content, the recalculated values were equal to the partial atmospheric pressure (Figure 5a) with a maximum discrepancy equal to $\pm 0.006 \mathrm{~atm}$, smaller than the instrumental uncertainty $( \pm 0.023 \mathrm{~atm})$. The recalculated partial pressures for oxygen were lower than its common value for air-saturated water because the tests were carried out in water where oxygen had been consumed in bacterial processes However, the data are characterized by a low uncertainty, which is equal to $0.005 \mathrm{~atm}$.

[21] A third test was carried out using sampling devices with tubes of the same length. Five devices were left in ASW for 24 hours and a second set of five devices were left for 64 hours. The variation in atmospheric pressure was measured throughout the experiment with a mean value equal to $0.998 \pm$ $0.005 \mathrm{~atm}$. The analytical uncertainty, expressed by standard deviation $\left(\sigma_{\mathrm{x}}\right)$, was computed by the square root of the variance of the set $\left(\sigma_{\mathrm{x}}^{2}\right)$ [Taylor, 1982], and this equaled $\pm 0.011 \mathrm{~atm}$ for the nitrogen and $\pm 0.007 \mathrm{~atm}$ for the oxygen. Precision, expressed as relative uncertainty, was computed by a standard deviation of the set and divided by the average of the set; it was found to be $1.5 \%$ for $\mathrm{N}_{2}$ and $3.7 \%$ for $\mathrm{O}_{2}$. The "true value" for $\mathrm{N}_{2}$ partial pressure was calculated by the product of measured barometric pressure $(0.998 \mathrm{~atm})$, for the $\mathrm{N}_{2}$ molar fraction in the atmosphere (0.78), and resulted equal to $0.778 \mathrm{~atm}$. Therefore the method accuracy for $\mathrm{N}_{2}$ was determined compared this "true value" with the average over the set (the so-called "best value"). The results for nitrogen, summarized in Figure 5b, suggest that the methodology is characterized by good precision and reproducibility, since the computed nitrogen partial pressures are very close to the "true value."

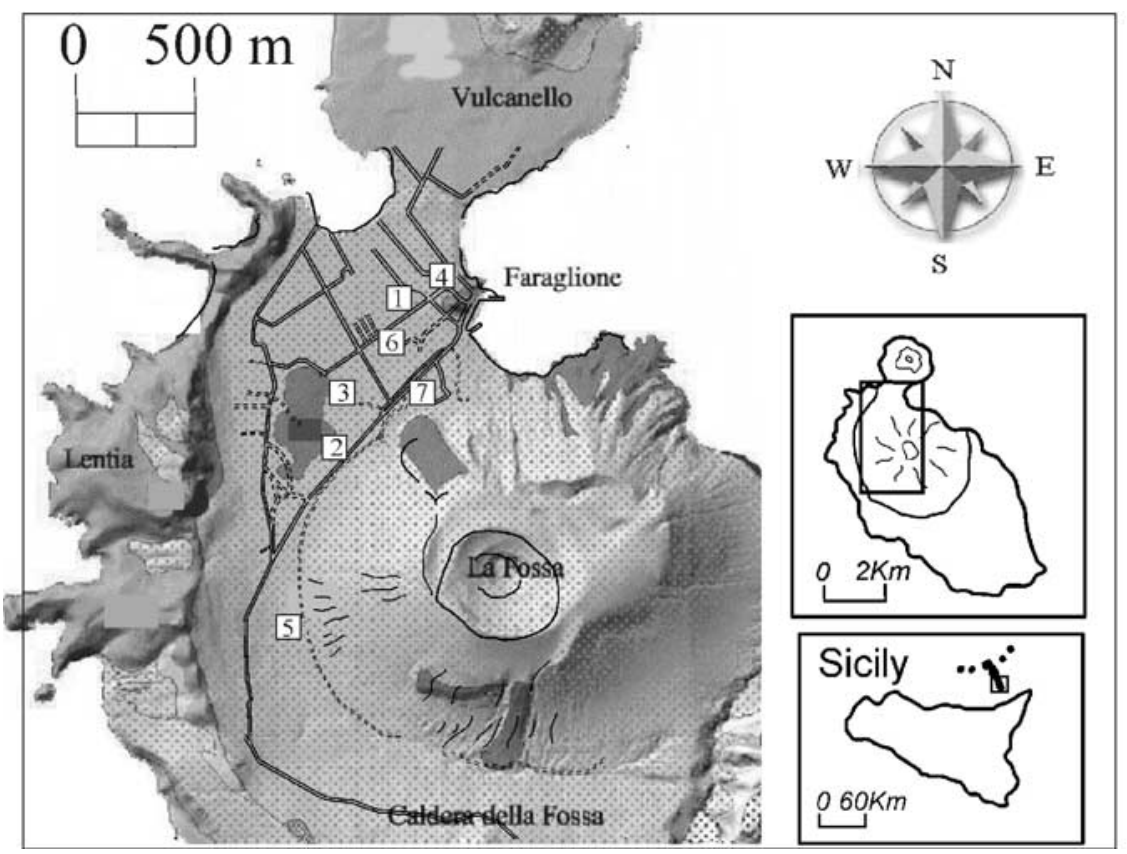

Figure 6. Location of sampling wells on Vulcano Island: 1, Bambara; 2, C. Sicilia; 3, Le Calette; 4, Castello; 5, Discarica; 6, Casmento; 7, Rifici. The numbers are the same as those in Table 3. 
Table 3. Physicochemical Parameters of Waters and Chemical Composition of Dissolved Gases From Vulcano Wells

\begin{tabular}{|c|c|c|c|c|c|c|c|c|c|c|c|}
\hline Number $^{\mathrm{a}}$ & Sample & Date & $\mathrm{T},{ }^{\circ} \mathrm{C}$ & $\mathrm{pH}$ & $\begin{array}{l}\text { Cond., } \\
\mathrm{mS} \mathrm{cm}^{-1}\end{array}$ & Eh, mV & $\mathrm{N}_{2}$, atm & $\mathrm{O}_{2}, \mathrm{~atm}$ & $\mathrm{CO}_{2}$, atm & $\mathrm{CH}_{4} \cdot 10^{4}$, atm & PT, atm \\
\hline 1 & Bambara & May 2003 & 25.7 & 5.68 & 1.6 & 153 & 0.22 & 0.02 & 0.77 & 0.92 & 1.01 \\
\hline 2 & C. Sicilia & May 2003 & 53.6 & 6.04 & 2.5 & 140 & 0.69 & 0.03 & 0.01 & 1.89 & 0.72 \\
\hline 2 & C. Sicilia & May 2003 & 53.6 & 6.04 & 2.5 & 140 & 0.71 & 0.03 & 0.01 & 2.24 & 0.75 \\
\hline 3 & Le Calette & May 2003 & 31.9 & n.d & n.d & n.d & 0.96 & 0.13 & 0.02 & $\leq 02$ & 1.12 \\
\hline 4 & Castello & May 2003 & 49.7 & 5.7 & 39.7 & -206 & 0.07 & 0.00 & 0.90 & $\leq 02$ & 0.97 \\
\hline 5 & Discarica & May 2003 & 49.4 & 6.60 & 4.29 & -136 & 0.21 & 0.03 & 0.70 & 2.20 & 0.94 \\
\hline 6 & Casamento & May 2003 & 24.7 & 6.77 & 1.89 & 50 & 0.78 & 0.14 & 0.15 & $\leq 02$ & 1.08 \\
\hline 6 & Casamento & May 2003 & 24.7 & 6.77 & 1.89 & 50 & 0.81 & 0.17 & 0.18 & $\leq 02$ & 1.16 \\
\hline 7 & Rifici & May 2003 & 28.2 & n.d & n.d & n.d & 0.77 & 0.17 & 0.01 & $\leq 02$ & 0.95 \\
\hline 1 & Bambara & July 2003 & 28.2 & 5.67 & 1.64 & 239 & 0.36 & 0.03 & 0.81 & 1.36 & 1.20 \\
\hline 2 & C. Sicilia & July 2003 & 53.6 & 7.70 & 8.4 & 162 & 0.64 & 0.02 & 0.01 & 1.31 & 0.67 \\
\hline 3 & Le Calette & July 2003 & 32.3 & n.d & n.d & n.d & 0.88 & 0.04 & 0.12 & 0.27 & 1.04 \\
\hline 4 & Castello & July 2003 & 50.2 & 5.82 & 37.1 & -198 & 0.29 & 0.03 & 0.89 & 1.28 & 1.21 \\
\hline 5 & Discarica & July 2003 & 48.8 & 6.60 & 4.42 & -39 & 0.14 & 0.00 & 0.75 & 2.76 & 0.89 \\
\hline 5 & Discarica & July 2003 & 48.8 & 6.60 & 4.42 & -39 & 0.15 & 0.00 & 0.75 & 3.30 & 0.91 \\
\hline 6 & Casamento & July 2003 & 27.0 & 5.97 & 1.98 & 227 & 0.55 & 0.09 & 0.30 & 2.93 & 0.94 \\
\hline 6 & Casamento & July 2003 & 27.0 & 5.97 & 1.98 & 227 & 0.57 & 0.09 & 0.30 & 2.70 & 0.96 \\
\hline
\end{tabular}

${ }^{\mathrm{a}}$ The numbers correspond to the well locations shown in Figure 6. The consecutive equal numbers refer to two samples collected in the same well at the same time.

[22] Owing to the high PTFE permeability of He, its equilibration time is fast. Regarding the geometric characteristics of the sampling devices used in this test, the He equilibration time was approximately 24 hours; after this time, all kinetic fractioning process should cease. The accuracy of the method for He isotopic composition was also tested, following the aforementioned procedure. Table 2 shows the results expressed as $\mathrm{R} / \mathrm{Ra}$ value. All the samples provide a value of $\mathrm{R} / \mathrm{Ra}$ which is very close to 1 (the value belonging to the atmospheric helium source). This result confirms the absence of any kinetic fractionation process at least for 12 hours, and confirms reliable reproducibility of the method for the helium isotope.

\section{Field Application}

[23] This method was applied to a volcanic context (Vulcano Island) where the circulating groundwater interacts with fluids of different natures [Tedesco and Nagao, 1996; Capasso et al., 1997, 2001; Cortecci et al., 2001]. Vulcano Island is the southernmost volcanic island in the Aeolian archipelago, located in the southern Tyrrhenian Sea (southern Italy) off the north coast of Sicily (Italy). The evolution of these volcanic islands is linked to the presence of an active crustal discontinuity [Ventura, 1994], corresponding to the NNW-SSEtrending dextral strike-slip fault system which is named Tindari-Letojanni [Ghisetti, 1979], a continuation of the Malta Escarpment. According to Favara et al. [1997], the Vulcano Porto phreatic aquifer is fed by groundwater which mainly comes from the Vulcano Piano area in the southern part of the island at about $400 \mathrm{~m}$ elevation a.s.l., and subordinately from the volcanic cone. The aquifer rock permeability is high, as supported by rapid drainage in the underground of heavy rains and the quick restoration of the static level in the wells after exploitation. There are four main groups of groundwater on Vulcano island [Bolognesi and D'Amore, 1993; Aiuppa et al., 2000]. Seven wells on the island (Figure 6) were selected on the basis of their chemical composition, which represents all water groups: (1) Le Calette, Discarica and Bambara (bicarbonate waters, warmer and saline rich);

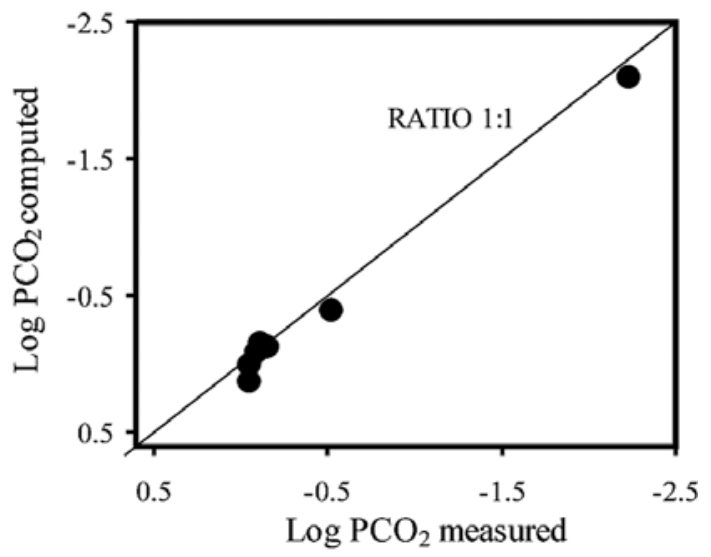

Figure 7. Comparison between the $\log$ of $\mathrm{CO}_{2}$ partial pressure values, measured by the new method and calculated by PHREEQC computer code for the samples collected in May and July 2003 from Vulcano wells. 


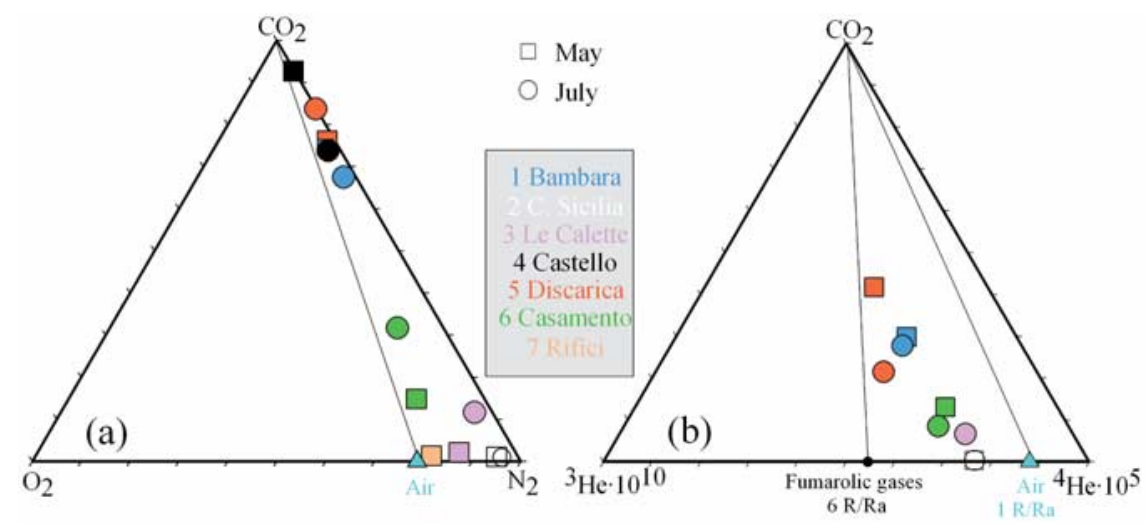

Figure 8. (a) $\mathrm{O}_{2}-\mathrm{CO}_{2}-\mathrm{N}_{2}$ triangular plot. The point relating to air composition (the triangle) and the line with $\mathrm{N}_{2} / \mathrm{O}_{2}$ atmospheric ratio are also shown. (b) $\mathrm{CO}_{2}$ and He isotope triangular plot. The point relating to $\mathrm{R} / \mathrm{Ra}$ of air $(\mathrm{R} / \mathrm{Ra}=1)$ and fumarolic gas from crater $(\mathrm{R} / \mathrm{Ra}=6)$ are also shown. Both plots highlight the mixing phenomena between the atmospheric gases and gases of deep and/or radiogenic origin.

Casamento (bicarbonate water, hypothermal and diluted); (2) C. Sicilia (chloride-sulfate groundwater); (3) Castello (chloride-rich water); (4) Rifici ( $\mathrm{SO}_{4}$-rich waters or steam-heated groundwater).

[24] In order to investigate both the spatial and time variations in the dissolved gas phase, the wells were sampled in May and July 2003, by using devices with PTFE tubes which were $90 \mathrm{~cm}$ in length. The devices were pre-evacuated and dipped into the wells for approximately 24 hours. Table 3 shows the physicochemical parameters of the waters and the chemical composition of dissolved gases. In some wells two samples were collected simultaneously and this shows that the method has good reproducibility in the field. In order to further investigate the applicability of the method, the $\mathrm{CO}_{2}$ partial pressure values, which had been measured by the proposed method, were compared with the values calculated by the PHREEQC computer code [Parkhurst, 1995], using the chemical composition of the waters. As suggested by Figure 7, an acceptable concordance was found to exist between two data sets.

[25] The dissolved gases in the groundwater of Volcano Island can be interpreted as a mixture of two components, one atmospheric and the other $\mathrm{CO}_{2}$-rich of deep origin. This mixing is clearly highlighted by the $\mathrm{O}_{2}-\mathrm{CO}_{2}-\mathrm{N}_{2}$ triangular plot (Figure 8a) where the samples are aligned along a mixing line between atmospheric gases and a $\mathrm{CO}_{2}$-rich member. Furthermore, all the samples have a $\mathrm{N}_{2} / \mathrm{O}_{2}$ ratio which is higher than the atmospheric one. This distribution could be due to two main processes: the organic and inorganic consumptions of $\mathrm{O}_{2}$ and/or the presence of a deep $\mathrm{N}_{2}$ component. The presence of deep nitrogen flux in a volcanic context is well documented, e.g., in island arc fluids, Sano et al. [2001] has recognized three nitrogen components: mantle-derived, sedimentary and atmospheric. Figure $8 \mathrm{~b}$ shows the $\mathrm{CO}_{2},{ }^{3} \mathrm{He}$ and ${ }^{4} \mathrm{He}$ triangular plot, where the helium concentrations also include the air component. Two

Table 4. Helium Data ${ }^{\mathrm{a}}$

\begin{tabular}{lccccc}
\hline \multicolumn{1}{c}{ Sample } & Date & $\mathrm{R} / \mathrm{Ra}$ & ${ }^{4} \mathrm{He} /{ }^{20} \mathrm{Ne}$ & $\mathrm{R} / \mathrm{Ra} \mathrm{c}$ & $\mathrm{PHe} 10^{5}, \mathrm{~atm}$ \\
\hline Bambara & May 03 & 3.41 & 2.347 & 3.83 & 1.06 \\
C. Sicilia & May 03 & 2.21 & 0.654 & 3.61 & 1.37 \\
Discarica & May 03 & 4.82 & 1.992 & 5.60 & 0.48 \\
Casamento & May 03 & 2.59 & 1.134 & 3.32 & 0.85 \\
Bambara & July 03 & 3.69 & 3.531 & 3.98 & 1.23 \\
C. Sicilia & July 03 & 2.20 & 0.564 & 4.11 & 1.26 \\
Discarica & July 03 & 5.26 & 4.937 & 3.58 & 1.33 \\
Casamento & July 03 & 2.97 & 0.698 & 3.81 & 1.99 \\
Le Calette & July 03 & 2.23 & 0.09 & \\
\hline
\end{tabular}

${ }^{\mathrm{a}} \mathrm{The} \mathrm{R} / \mathrm{Ra}$, corrected with respect to atmospheric gases denoted as $\mathrm{R} / \mathrm{Ra} \mathrm{c}$, was computed using the atmospheric ${ }^{20} \mathrm{Ne}$ concentration, according to Polyak [2003]. 


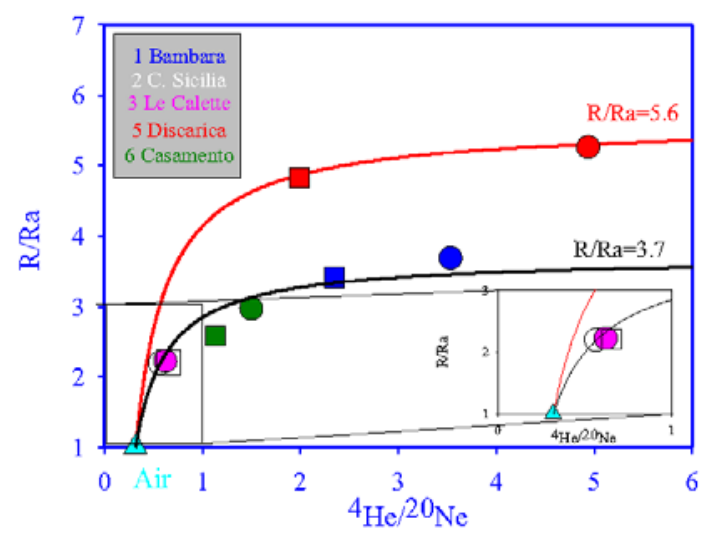

Figure 9. Correlation diagram $\mathrm{R} / \mathrm{Ra}$ versus ${ }^{4} \mathrm{He} /{ }^{20} \mathrm{Ne}$. The curves show a mixing between air and two endmembers with $\mathrm{R} / \mathrm{Ra}=3.7$ (black line) and $\mathrm{R} / \mathrm{Ra}=5.6$ (red line). The sample distributions testify to the presence of both magmatic and radiogenic helium in the dissolved gases. The samples from the Discarica well seem to be less contaminated by the radiogenic component, given that it follows the red line.

lines, linking the vertex of $\mathrm{CO}_{2}$ with two isotopic ratios, $\mathrm{R} / \mathrm{Ra}=1$ and $\mathrm{R} / \mathrm{Ra}=6$, are also traced. The first $\mathrm{R} / \mathrm{Ra}$ value represents the atmospheric source while the second is the $\mathrm{R} / \mathrm{Ra}$ value, which was measured in the fumarolic gases from La Fossa Crater [Italiano and Nuccio, 1996]. All the samples fall between two straight lines, thereby reflecting a mixing process between a deep member, which is rich in $\mathrm{CO}_{2}$ and ${ }^{3} \mathrm{He}$, and the atmosphere. The differences in the He isotopic ratio (Table 4) can be ascribed to different mixing percentages between "deep" end-members and atmospheric ones. The ${ }^{4} \mathrm{He} /{ }^{20} \mathrm{Ne}$ ratio in the atmosphere is well known and constant. Assuming an end-member with $\mathrm{R} / \mathrm{Ra}=$ 1 and ${ }^{4} \mathrm{He} /{ }^{20} \mathrm{Ne}_{\text {atm, }}$ it is therefore possible to derive mixing curves between end-members with various $\mathrm{R} / \mathrm{Ra}$ and the atmospheric one. From Figure 9, the presence of mixing processes between atmospheric gases and two end-members with an $\mathrm{R} / \mathrm{Ra}$ equal to 3.7 and 5.6 respectively is evident. The last $\mathrm{R} / \mathrm{Ra}$ value is very close to the value of gases emitted from La Fossa Crater fumaroles [Italiano and Nuccio, 1996; Tedesco and Nagao, 1996]. The other R/Ra value is likely to be indicative of the contamination of the deep component with a radiogenic helium source $\left({ }^{4} \mathrm{He}\right)$. The presence of a radiogenic helium component in fluids emitted in volcanic areas is rather common. Generally, ${ }^{4} \mathrm{He}$ is linked to rock with high concentrations of radiogenic elements like $\mathrm{U}$ and Th. These elements are enriched in the last phases of crystallization so acid rocks bear higher concentrations of these elements. These types of rocks are widely outcropping on Vulcano island. Moreover, the elevated presence of radiogenic components has also been highlighted by various studies on $\gamma_{\text {ray }}$ emission in the Aeolian archipelago [Brai et al., 1995; Chiozzi et al., 2001] and on the trace element contents in the groundwaters of Vulcano [Aiuppa et al., 2000]. The latter study highlights the presence of intense leaching processes in rocks which are rich in radiogenic elements in this area.

\subsection{Temporal Variations}

[26] The helium data demonstrate the most meaningful time variations. In order to clarify the behavior of dissolved helium, the percentage of different components of dissolved helium was computed (Table 5). The triangular plot in Figure 10 shows the differences between the two temporal sets. Excluding the C. Sicilia well, the amount of deep helium increased from May to July in all the other samples. These data also highlighted an increase in radiogenic helium. On the contrary, the dissolved gases from C. Sicilia showed an increase in the atmospheric component between May and July, even if the $\mathrm{R} / \mathrm{Ra}$ value remained constant. This unusual condition can be explained by a con-

Table 5. Percentages of Different Helium Components ${ }^{\mathrm{a}}$

\begin{tabular}{lcccc}
\hline Sample & Date & \% atm & \% rad & Deep \\
\hline Bambara & May 03 & 14.8 & 30.9 & 54.3 \\
Bambara & July 03 & 9.7 & 30.4 & 59.8 \\
C. Sicilia & May 03 & 53.6 & 18.5 & 27.9 \\
C. Sicilia & July 03 & 61.4 & 12.2 & 26.4 \\
Casamento & May 03 & 31.5 & 30.7 & 37.9 \\
Casamento & July 03 & 23.6 & 30.8 & 45.5 \\
Discarica & May 03 & 17.0 & 6.5 & 77.5 \\
Discarica & July 03 & 7.0 & 16.0 & 86.5 \\
Le Calette & July 03 & 56.2 & 27.8 \\
\hline
\end{tabular}

\footnotetext{
${ }^{\mathrm{a}}$ In order to compute the He components, the value $\mathrm{R} / \mathrm{Ra}=0.01$ was used as a radiogenic end-member [Mamyrin and Tolstikhin, 1984], and $\mathrm{R} /$ $\mathrm{Ra}=6$ as a magmatic value [Italiano and Nuccio, 1996].
} 


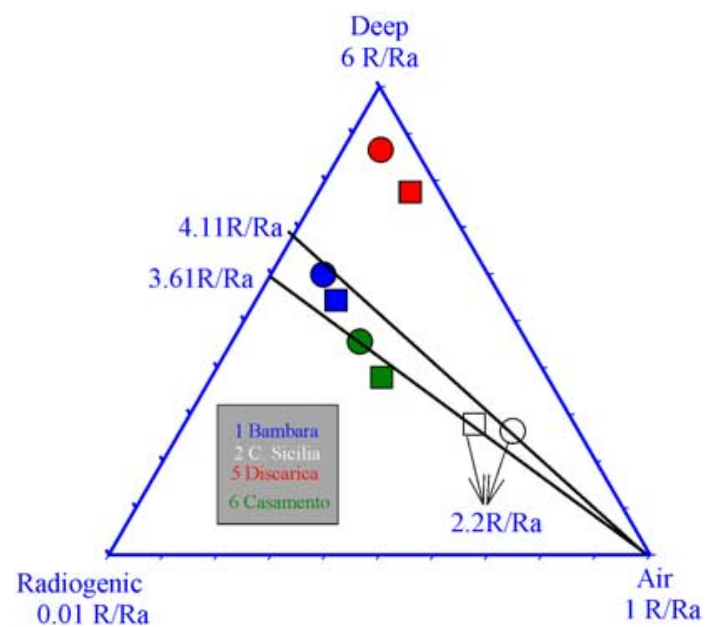

Figure 10. Variations between May (squares) and July (circles) of the helium components in Vulcano groundwater. The July samples have been shifted toward the side of nonatmospheric components, excluding C. Sicilia samples. Notwithstanding the increase in the air component in this well, the value of $\mathrm{R} / \mathrm{Ra}$ remained constant $(2.2 \mathrm{R} / \mathrm{Ra})$ between May and July because the value of corrected $\mathrm{R} / \mathrm{Ra}$ increased from 3.61 to 4.11 , as shown on the left-hand side of the triangle. The graphic feature indicated an input of helium of deep origin.

comitant input of deep ${ }^{3} \mathrm{He}$, as confirmed by an increase in $\mathrm{Ra} / \mathrm{Ra}_{\mathrm{c}}$ ( $\mathrm{R} / \mathrm{Ra}$ corrected by the atmospheric component) from 3.6 to 4.1 ; in short, the increase in the atmospheric component diluted the input of deep ${ }^{3} \mathrm{He}$ in this well. The deep input is also indicated by an increase in $\mathrm{CO}_{2}$ partial pressure.

[27] As has been well documented by several authors [Carapezza et al., 1980; Capasso et al., 1991; Bolognesi, 2000], both seismic and volcanic activities can determine time variations in the chemical and isotopic composition of the fluids emitted in this area. The time variations in the Helium isotopic composition and $\mathrm{CO}_{2}$ contents may also be linked to a seismic event of magnitude 3.0 which occurred $24 \mathrm{~h}$ prior to the second sampling survey, a few miles north of the island.

\section{Conclusion}

[28] In this paper a polymeric membrane made of PTFE, gas-permeable and waterproof, was used to separate the dissolved gaseous phase from water. The processes involved in the permeation of gas through the PTFE were modeled according to the "Solution-Diffusion Model." Commencing with this model and applying a mass balance, a theoretical model were developed. The equations of the model related the partial pressure inside the device at any time with the equilibrium partial pressure of dissolved gases.

[29] A new sampling device was developed, which is constituted by two interconnected parts, a glass sample-holder (where the gas sample is preserved) and a semipermeable membrane, where the gas can permeate into the device. The theoretical model was used to elaborate a mathematical method to recalculate (R.M.) the equilibrium partial pressure of each gaseous species inside the sampling device, using the composition of gas that still had not reached equilibrium. Experimental data of partial pressure variations with time inside the device were obtained, and a comparison between theoretical and experimental data gave very good results. Furthermore, several laboratory tests have highlighted the accuracy and precision of the methodology proposed in this paper.

[30] This method was applied to a volcanic area (Vulcano Island) from which several samples of dissolved gases were collected and each of them analyzed for both chemical and isotopic composition. The composition of dissolved gases in the analyzed wells highlighted their origin and this could be explained as the mixing of almost three different components: the first comprises atmospheric gases, the second derives from a deep magmatic reservoir and the final component is of crustal origin. Finally, temporal variations in chemical and isotopic composition were recorded and they seem to be related to an earthquake $(\mathrm{M}=3)$ which occurred very close to the island $24 \mathrm{~h}$ hour prior to the July sampling survey.

\section{Acknowledgments}

[31] This work was supported by the European Social Fund. Critical comments and helpful suggestions by Bruce Anderson, David R. Hilton, Marvin Lilley, and an anonymous reviewer greatly improved the manuscript.

\section{References}

Aeschbach-Hertig, W., F. Peeters, U. Beyerle, and R. Kipfer (1999), Interpretation of dissolved atmospheric noble gases in natural waters, Water Resour. Res., 35(9), 2779-2792.

Aiuppa, A., G. Dongarrà, G. Capasso, and P. Allard (2000), Trace elements in thermal groundwaters of Vulcano Island (Sicily), J. Volcanol. Geotherm. Res., 98, 189-207.

Allard, P., P. Jean-Baptiste, W. D'Alessandro, F. Parello, B. Parisi, and C. Flehoc (1997), Mantle-derived helium and carbon in groundwaters and gases of Mount Etna, Italy, Earth Planet. Sci. Lett., 148, 501-516. 
Andrews, J. N., J. E. Goldbrunner, W. G. Darling, G. B. Hooker, M. J. Youngman, L. Eichinger, W. Rauert, and W. Stichler (1985), A radiochemical, hydrochemical and dissolved gas study of groundwaters in the Molasse basin of Upper Austria, Earth Planet. Sci. Lett., 73, 317-332.

Andrews, J. N., N. Hussain, and M. J. Youngman (1989), Atmospheric and radiogenic gases in groundwaters from stripa granite, Geochim. Cosmochim. Acta, 53, 1831-1841.

Barrer, R. M. (1934), Permeation, diffusion and solution of gases in organic polymers, Trans. Faraday Soc., 35, 628643.

Bayer, R., P. Schlosser, G. Bönisch, H. Rupp, F. Zaucker, and G. Zimmek (1989), Performance and blank components of a mass spectrometric system for routine measurement of helium isotopes and tritium by the ${ }^{3} \mathrm{He}$, in Growth Method, pp. 241-279, Springer, New York.

Beyerle, U., I. W. Aeschbach-Herting, D. M. Imboden, H. Baur, T. Graf, and R. Kipfer (2000), A mass spectrometric system for the analysis of noble gases and tritium from water samples, Environ. Sci. Technol., 34, 2042-2050.

Bolognesi, L. (2000), Earthquake-induced variations in the composition of the water in the geothermal reservoir at Vulcano Island, Italy, J. Volcanol. Geotherm. Res., 99, 139-150.

Bolognesi, L., and F. D'Amore (1993), Isotopic variation of the hydrothermal system on Vulcano Island, Italy, Geochim. Cosmochim. Acta, 57, 2069-2082.

Brai, M., S. Hauser, S. Bellia, P. Puccio, and S. Rizzo (1995), Natural gamma radiation of rocks and soils from Vulcano, Nucl. Geophys., 9, 121-127.

Capasso, G., and S. Inguaggiato (1998), A simple method for determination of dissolved gases in natural water: An application to thermal waters from Vulcano Island, Appl. Geochem., 13(5), 631-642.

Capasso, G., G. Dongarrà, R. Favara, S. Hauser, and M. Valenza (1991), Chemical changes in waters from Vulcano Island: An update, Acta Vulcanol., 1, 199-209.

Capasso, G., R. Favara, and S. Inguaggiato (1997), Chemical features and isotopic composition of gaseous manifestations on Vulcano Island, Aeolian Islands, Italy: An interpretative model of fluid circulation, Geochim. Cosmochim. Acta, 61, 3425-3440.

Capasso, G., R. Favara, and S. Inguaggiato (2000), Interaction between fumarolic gases and thermal groundwaters at Vulcano Island (Italy): Evidences from chemical composition of dissolved gases in waters, J. Volcanol. Geotherm. Res., 102, 309-318.

Capasso, G., W. D’Alessandro, R. Favara, S. Inguaggiato, and F. Parello (2001), Interaction between deep fluids and the shallow groundwaters on Vulcano Island, J. Volcanol. Geotherm. Res., 108, 187-198.

Carapezza, M., P. M. Nuccio, and M. Valenza (1980), Geochemical Precursor of Earthquakes: High Pressure Science and Technology, edited by B. Vodar and Ph. Marteau, Elsevier, New York.

Chapelle, F. H., D. A. Vroblesky, J. C. Woodward, and D. R. Lovley (1997), Practical considerations for measuring hydrogen concentrations in groundwater, Environ. Sci. Technol., $31,2873-2877$.

Chiodini, G. (1996), Gases dissolved in groundwaters: Analytical methods and examples of applications in central Italy, paper presented at Rome Seminar on Environmental Geochemistry, Univ. degli Studi di Genova Dip. di Sci. della Terra, Rome, 22-26 May.

Chiozzi, P., V. Pasquale, M. Verdoya, and S. Minato (2001), Natural gamma-radiation in the Aeolian volcanic arc, Appl. Radiat. Isotopes, 55, 737-744.
Cortecci, G., E. Dinelli, L. Bolognesi, T. Boschetti, and G. Ferrara (2001), Chemical and isotopic compositions of water and dissolved sulfate from shallow wells on Vulcano Island, Aeolian Archipelago, Italy, Geothermics, 30, 69-91.

D’Alessandro, W., S. De Gregorio, G. Dongarrà, S. Gurrieri, F. Parello, and B. Parisi (1997), Chemical and isotopic characterization of the gases of Mount Etna, J. Volcanol. Geotherm. Res., 78, 65-76.

Emerson, S., C. Stump, B. Johnson, and D. M. Karl (2002), In situ determination of oxygen and nitrogen dynamics in the upper ocean, Deep Sea Res., Part I, 49, 941-952.

Favara, R., S. Francofonte, P. Madonia, and M. Valenza et al. (1997), Modello idrogeologico dell'Isola di Vulcano e suo signifcato per la sorveglianza geochimica, in Program and Abstracts of GNV-CNR Annual Meeting 1996, Rome 3-5 March, pp. 162-163, Gruppo Nazl. per la Vulcanol., Rome. Ghisetti, F. (1979), Relazioni tra strutture e fasi trascorrenti e distensive lungo i sistemi Messina-Fiumefreddo, TindariLetojanni e Alia-Malvagna (Sicilia nord-orientale): Uno studio microtettonico, Geol. Romana, 18, 23-58.

Gurrieri, S., S. Hauser, and M. Valenza (1984), Indagine preliminare su alcune sorgenti termali della Calabria per una futura sorveglianza geochimica, Miner. Petrogr. Acta, 28, $101-122$.

Holt, B. D., N. C. Sturchio, G. B. Arehart, and A. J. Bakel (1995), Ultrasonic vacuum extraction of gases from water for chemical and isotopic analysis, Chem. Ecol., 122, 275-284.

Inguaggiato, S., and A. Rizzo (2004), Dissolved helium isotope ratios in ground-waters: A new technique based on gaswater re-equilibration and its application to a volcanic area, Appl. Geochem., 19(5), 665-673.

Italiano, F., and P. M. Nuccio (1996), Isotopic ratios of helium in fumaroles from Vulcano Island, Acta Vulcanol., 8(2), $212-214$

Italiano, F., G. Martinelli, and A. Rizzo (2004), Geochemical evidence of seismogenic-induced anomalies in the dissolved gases of thermal waters: A case study of Umbria (Central Apennines, Italy) both during and after the 1997-1998 seismic swarm, Geochem. Geophys. Geosyst., 5, Q11001, doi:10.1029/2004GC000720.

Jacinthe, P. A., and P. M. Groffman (2001), Silicone rubber sampler to measure dissolved gases in saturated soils and waters, Soil Biol. Biochem., 33, 907-912.

Kampbell, D. H., J. T. Wilson, and D. M. McInnes (1998), Determining dissolved hydrogen, methane, and vinyl chloride concentrations in aqueous solution on a nanomolar scale with the bubble strip method, paper presented at 1998 Conference on Hazardous Waste Research, Hazard. Substance Res. Cent., Kansas State Univ., Snowbird, Utah, 18-21 May.

Kana, T. M., C. Darkangelo, M. D. Hunt, J. B. Oldham, G. E. Bennett, and J. C. Cornwell (1994), Membrane inlet mass spectrometer for rapid high-precision determination of $\mathrm{N}_{2}$, $\mathrm{O}_{2}$, and $\mathrm{Ar}$ in environmental water samples, Anal. Chem., 66, 4166-4170.

Ludin, A., R. Weppernig, G. Boenisch, and P. Schlosser (1997), Mass spectrometric measurement of helium isotopes and tritium, technical report, Lamont-Doherty Earth Observatory, Palisades, N. Y.

Mamyrin, B. A., and I. N. Tolstikhin (1984), Helium Isotopes in Nature, 274 pp., Elsevier, New York.

Manning, A. H., and D. K. Solomon (2003), Using noble gases to investigate mountain-front recharge, J. Hydrol., 275, 194-207.

Manning, A. H., A. L. Sheldon, and D. K. Solomon (2000), A new method of noble gas sampling that improves excess air 
determinations, Eos Trans. AGU, 81(48), Fall Meet. Suppl., Abstract H71A-09.

Mazor, E. (1977), Geothermal tracing with atmospheric and radiogenic noble gases, Geothermics, 5, 21-36.

McNeil, C. L., B. D. Johnson, and D. M. Farmer (1995), In-situ measurement of dissolved nitrogen and oxygen in the ocean, Deep Sea Res., Part I, 42, 819-826.

Ozima, M., and F. A. Podosek (2002), Noble Gas Geochemistry, 2nd ed., 286 pp., Cambridge Univ. Press, New York.

Parkhurst, D. L. (1995), User's guide to PHREEQC-A computer program for speciation, reaction-path, advectivetransport, and inverse geochemical calculations, U.S. Geol. Surv. Water Resour. Invest. Rep., 95-4227, 143 pp.

Peeters, F., U. Beyerle, W. Aeschbach-Hertig, J. Holocher, M. S. Brennwald, and R. Kipfer (2002), Improving noble gas based paleoclimate reconstruction and groundwater dating using ${ }^{20} \mathrm{Ne} /{ }^{22} \mathrm{Ne}$ ratios, Geochim. Cosmochim. Acta, 67(4), 587-600.

Polyak, B. G. (2003), Helium isotopes in the ground fluids of the Baikal Rift and its surroundings: Contribution to continental rifting geodynamics, Russ. J. Earth Sci., 5(1).

Sanford, W. E., R. G. Shropshire, and K. D. Solomon (1996), Dissolved gas tracers in groundwater: Simplified injection, sampling, and analysis, Water Resour. Res., 32(6), 16351642.

Sano, Y., N. Takahata, G. Igarashi, N. Koizumi, and N. C. Sturchio (1998), Helium degassing related to the Kobe earthquake, Chem. Geol., 1501, 171-179.

Sano, Y., N. Takahata, Y. Nishio, T. B. Fischer, and S. N. Williams (2001), Volcanic flux of nitrogen from the Earth, Chem. Geol., 171, 263-271.

Solomon, D. K., P. G. Cook, and W. E. Sanford (1998), Dissolved gases in subsurface hydrology, in Isotope Tracers in Catchment Hydrology, edited by C. Kendall and J. J. McDonnell, pp. 291-318, Elsevier, New York.
Stute, M., J. F. Clark, P. Schlosser, and W. S. Broecker (1995), A 30,000 yr continental paleotemperature record derived from noble gases dissolved in groundwater from the San Juan Basin, New Mexico, Quat. Res., 43, 209-220.

Sugisaki, R., and K. Taki (1987), Simplified analyses of He, $\mathrm{Ne}$ and $\mathrm{Ar}$ dissolved in natural waters, Chem. J., 21, $21-$ 27.

Takahata, N., G. Igarashi, and Y. Sano (1997), Continuous monitoring of dissolved gas concentrations in groundwater using a quadrupole mass spectrometer, Appl. Geochem., 12, 377-382.

Taylor, J. R. (1982), An Introduction to Error Analysis: The Study of Uncertainties in Physical Measurements, 2nd ed., 327 pp., Univ. Sci. Books, Mill Valley, Calif.

Tedesco, D., and K. Nagao (1996), Radiogenic ${ }^{4} \mathrm{He},{ }^{21} \mathrm{Ne}$ and ${ }^{40} \mathrm{Ar}$ in fumarolic gases on Vulcano: Implication for presence of continental crust beneath the island, Earth Planet. Sci. Lett., 144, 517-528.

Tonani, F. (1971), Concepts and techniques for the geochemical forecasting of volcanic eruption, UNESCO Paris 145 166 Geol. Bull., 41(3/4), 309-322.

Van Amerongen, G. J. (1946), The permeability of different rubbers to gases and its relation to diffusivity and solubility, J. Appl. Phys., 17, 972-986.

Ventura, G. (1994), Tectonics, structural evolution and caldera formation on Vulcano Island (Aeolian Archipelago, southern Tyrrhenian Sea), J. Volcanol. Geotherm. Res., 60, 207-224.

Walsh, K. P., and R. G. McLaughlan (1999), Bubble extraction of dissolved gases from groundwater samples, Water Air Soil Pollut., 115, 525-534.

Weiss, R. F. (1968), Piggyback samplers for dissolved gas studies on sealed water samples, Deep Sea Res. Oceanogr. Abstr., 15, 695-699.

Wijmans, J. G., and R. W. Baker (1995), The solution diffusion model: A review, J. Membrane Sci., 107, 1-21. 